\title{
Retention of a telescopic overdenture on customized abutments after the simulation of 1 year in function
}

\author{
Rania Ramadan ${ }^{1, A, B}$, Yasmine Elsherbeeny ${ }^{1, C, D}$, Yasmine Thabet ${ }^{1, E, F}$, Bassem Kandil ${ }^{2, C, D}$, Rami Ghali ${ }^{1, E, F}$ \\ ${ }^{1}$ Department of Oral and Maxillofacial Prosthodontics, Faculty of Dentistry, Ain Shams University, Cairo, Egypt \\ ${ }^{2}$ Department of Fixed Prosthodontics, Faculty of Dentistry, Ain Shams University, Cairo, Egypt \\ A - research concept and design; $\mathrm{B}$ - collection and/or assembly of data; $\mathrm{C}$ - data analysis and interpretation; \\ $\mathrm{D}$ - writing the article; $\mathrm{E}$ - critical revision of the article; $\mathrm{F}$ - final approval of the article
}

Address for correspondence

Bassem Kandil

E-mail: bassem.s.kandil@dent.asu.edu.eg

Funding sources

None declared

Conflict of interest

None declared

Received on July 27,2020

Reviewed on September 13, 2020

Accepted on September 29, 2020

Published online on April 29, 2021

\begin{abstract}
Background. Telescopic implant-retained overdentures are considered one of the most common treatment modalities for edentulous patients.

Objectives. The aim of the study was to evaluate the retention of a BioHPP (biocompatible highperformance polymer) telescopic overdenture supported by customized abutments made from 2 different materials after the simulation of 1 year in function.

Material and methods. Twelve models of a completely edentulous mandible were three-dimensionally (3D)-printed. Two implants and 2 groups of customized abutments - group Bio: BioHPP $(n=6)$ and group Ti: titanium $(n=6)$ - were used to support BioHPP telescopic overdentures. A vertically dislodging force was applied to each denture until its separation before and after 240,000 cycles of chewing simulation and 1,440 iterations of cyclic dislodgement for the simulation of 1 year in function in order to measure maximum tensile loads needed to dislodge the overdenture. Student's $t$ test and the paired $t$ test were used for the statistical analysis $(a=0.05)$.

Results. The initial and final retentive forces of the Ti group were significantly higher than in the case of the Bio group. A significant decrease in the retentive forces within the 2 groups after chewing simulation was observed and it was higher in group Ti; however, there was no statistically significant difference between the 2 groups.

Conclusions. The retentive force values for implant-retained telescopic overdentures significantly decreased after the simulation of 1 year of overdenture use. Both BioHPP and titanium are considered suitable abutment materials to retain telescopic overdentures.
\end{abstract}

Keywords: dental implants, titanium, overdenture, software design

Cite as

Ramadan R, Elsherbeeny Y, Thabet Y, Kandil B, Ghali R.

Retention of a telescopic overdenture on customized abutments

after the simulation of 1 year in function. Dent Med Probl.

2021;58(2):201-206. doi:10.17219/dmp/127963

DOI

$10.17219 / \mathrm{dmp} / 127963$

Copyright

๑ 2021 by Wroclaw Medical University

This is an article distributed under the terms of the

Creative Commons Attribution 3.0 Unported License (CC BY 3.0)

(https://creativecommons.org/licenses/by/3.0/). 


\section{Introduction}

Implant overdentures are the most common treatment modality for edentulous patients due to their efficacy in increasing retention, stability and masticatory performance, especially with the noted increased success rate in dental implant placement. ${ }^{1}$ Among different types of overdenture attachments, the telescopic attachments used with implant overdentures are considered interesting and unique, as they give the dental practitioner the possibility of achieving more esthetic results while using fewer implants with less restricted implant location, better access for oral hygiene measures, ${ }^{2,3}$ better horizontal stability due to their parallel wall design and exerting less torque, and better load distribution on the abutments due to their circumferential relation to the outer coping. ${ }^{4}$ Telescopic overdentures are classified according to their mechanism of retention into 3 categories: parallel, conical and hybrid telescopic with an added retentive feature. In the $1^{\text {st }}$ category, they gain retention through the friction of the parallel-milled surfaces. In the $2^{\text {nd }}$ category, they obtain retention through friction, but only after their final seating with the so-called 'wedging effect'. In hybrid telescopic systems, an added retentive feature, such as the TC-SNAP system (the Marburg double-crown system), is used. ${ }^{5,6}$

The materials used for manufacturing implant abutments should have desirable biological, mechanical and esthetic properties. Titanium, gold and zirconium are the most well-known materials used in prefabricated abutments. ${ }^{7}$ Titanium is considered the gold standard and is most frequently used, although it has several disadvantages, such as grayish color, corrosion susceptibility and oversensitivity reactions. ${ }^{8}$ Gold abutments are not used nowadays despite their great biocompatibility due to their high cost and poor attachment to the soft tissue collar around implant platforms, ${ }^{9}$ while zirconia abutments suffer from the risk of fracture of their apical part, ${ }^{10}$ inconsistent long-term survival ${ }^{11}$ and fretting wear. ${ }^{12}$

With the evolution of the computer-aided design and computer-aided manufacturing (CAD/CAM) technology, customized abutments are now easier to produce. The CAD/CAM process can optimally control the geometry of the abutment and adjust it to the optimum design to overcome the drawbacks of prefabricated abutments.

Customized abutments may be in the two-piece form (hybrid abutments); this type consists of a customized ceramic abutment that is cemented on a prefabricated titanium insert, ${ }^{13}$ providing the titanium-to-titanium contact for a better fit. Unfortunately, bonding these customized abutments to their titanium bases is technique-sensitive. ${ }^{14}$ Pre-milled abutments, which have been recently introduced into the dental market, are another option for abutment customization that could overcome the problems of previous offerings. These abutments are used in the digital production of CAD/CAM workflow, allowing the milling of implant abutments to a customized design with a pre-milled implant connection.

High-performance polymers are used nowadays in the fabrication of hybrid and pre-milled abutments. Biocompatible high-performance polymer (BioHPP) is one of such polymers; it offers a lot of unique properties, which makes it an interesting alternative to ceramic abutments. Its biocompatibility and excellent polishability ${ }^{15}$ have a great impact on preserving bone height and soft tissues, which results in better anchorage. ${ }^{16}$ It also has high mechanical and flexural strength, along with elasticity similar to bone. ${ }^{17}$ BioHPP can be fabricated via pressing or milling. The material properties of pressed and milled BioHPP are virtually identical. ${ }^{18}$

Unfortunately, there is little previous research comparing these new materials as telescopic abutments for the retention of implant overdentures. This study was conducted to evaluate the retention of a BioHPP telescopic overdenture supported by titanium pre-milled abutments and BioHPP customized abutments after the simulation of 1 year in function.

The null hypothesis of this study was that there is no difference between titanium pre-milled abutments and BioHPP customized abutments in the retentive force of the overdenture before and after the simulation of 1-year function.

\section{Material and methods}

\section{Model fabrication}

A three-dimensional (3D) model of a completely edentulous mandible was designed with 2 implant beds in the canine region, equidistant from the midline and perpendicularly aligned to the ultimate occlusal plane to accommodate two $4.2 \mathrm{~mm} \times 10 \mathrm{~mm}$ implants. A layer of a 2-millimeter thickness was removed from the surface of the model to be replaced with mucosa-simulating material later on. Twelve models were printed by means of an additive manufacturing technology. Two $4.2 \mathrm{~mm} \times 10 \mathrm{~mm}$ implants were cemented at their planned sites in each model with a delicate layer of cyanoacrylate adhesive cement.

\section{Mucosa simulation}

A wax build-up was done on the model over the designed space for mucosa simulation. Then, the duralay resin pattern (Pi-Ku-Plast ${ }^{\circledR}$ HP 36; Bredent Medical, Senden, Germany) was adapted on the wax layer to act as a matrix. Wax elimination was performed and siliconebased soft tissue-replicating material (Multisil-Mask ${ }^{\circledR}$ soft; Bredent Medical) was applied, while the matrix was fixed on the model. After the material was completely set, a scalpel was used to finish and trim the excess of the soft tissue material. 


\section{Abutment fabrication}

The Uni.fit scan abutments (Bredent Medical) were seated tightly on each implant and were scanned with a desktop scanner $\left(\operatorname{InEos}^{\circledR} \mathrm{X} 5\right.$; Sirona Dentsply, York, USA) to transfer the $3 \mathrm{D}$ implant position to the CAD software (Exocad, Darmstadt, Germany). In the CAD software, the design of the abutments was made, $4 \mathrm{~mm}$ in length with a wall taper angle of 2 degrees and a chamfer finish line. For the Bio group, wax was used for milling the abutments, which were invested and burnt out, and then BioHPP granules were pressed onto the titanium base, using the for-2-press system (Bredent Medical) to produce customized hybrid BioHPP abutments. For the Ti group, titanium prefab blanks (Bredent Medical), a type of premilled abutments, were used for milling. Six pairs from each group were fabricated and each pair was completely seated on the model. Figure 1 shows the final abutments on the model.
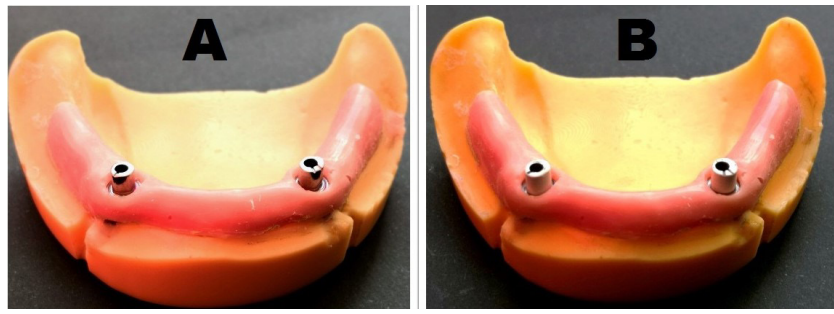

Fig. 1. Final abutments on the model

A - titanium; B - biocompatible high-performance polymer (BioHPP).

\section{Framework fabrication}

A wax pattern of a telescopic overdenture extending from the right first molar site to the left first molar site, including the secondary copings, was done for each model. The wax patterns were then invested and burnt out, and then BioHPP pellets were pressed using the for-2-press system to produce BioHPP frameworks. Each framework was finished and polished, and then returned to its model. Figure 2 shows the final BioHPP telescopic overdenture framework.

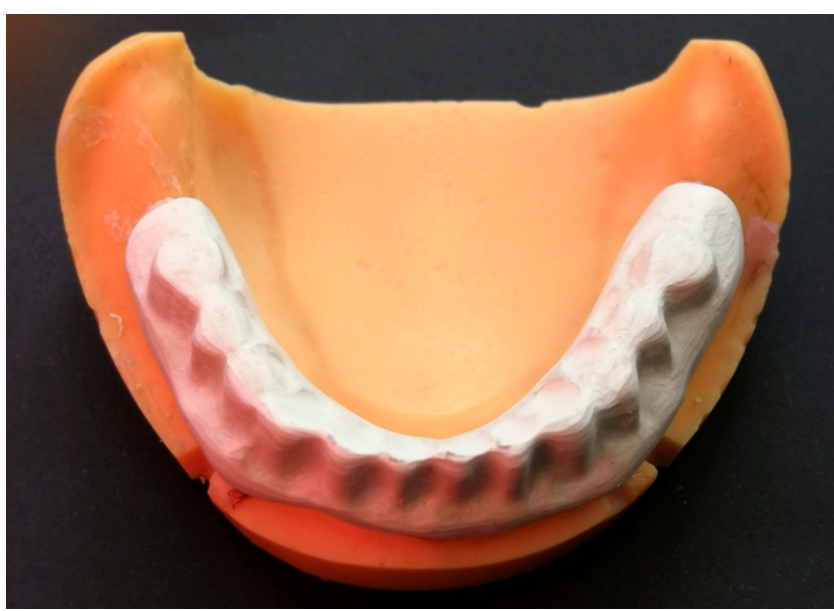

Fig. 2. Final BioHPP telescopic overdenture framework

\section{Testing}

A universal testing machine (Lloyd Instruments, Bognor Regis, UK) was used to apply vertical dislodging forces on a horizontal metal plate. A central hook was attached to the occlusal surface of each overdenture at a position $13 \mathrm{~mm}$ distal to the line passing through the implant center until it was elevated from its seating position. All groups were tested under the same conditions, i.e., moistening of the abutments and the fitting surface of the overdenture with artificial saliva (Glandosane ${ }^{\circledR}$; STADAPHARM, Laichingen, Germany), as recommended by Bayer et al., ${ }^{19}$ and loading the overdenture with a compressive pre-weight of $50 \mathrm{~N}$ for $20 \mathrm{~s}$. The machine was set at a constant crosshead speed of $50 \mathrm{~mm} / \mathrm{min}$. The initial pull-off test was done and maximum tensile loads needed to dislodge the overdentures from the cast model were calculated in newtons. Three measurements were performed for each overdenture and their mean was considered as the initial retentive value. Figure 3 shows the initial pull-off test.

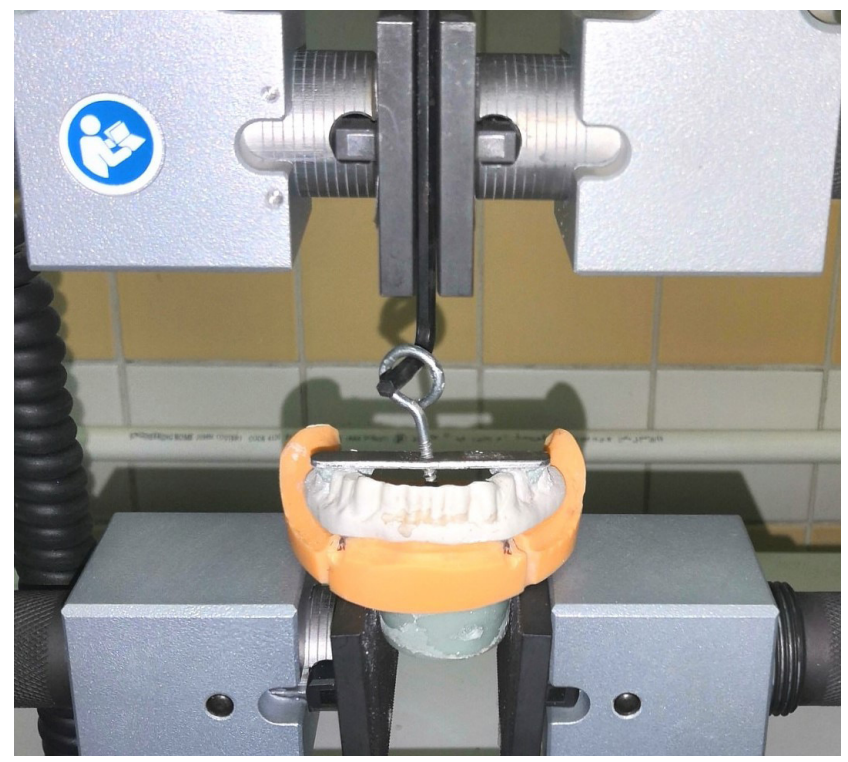

Fig. 3. Initial pull-off test

A chewing simulator (CS-4.4; SD Mechatronic, Munich, Germany) was used to apply dynamic/cyclic loading to each overdenture. The exact point of load application was marked at the center of the horizontal metal plate which was attached to the occlusal surface of each overdenture, as shown in Fig. 4. All groups were tested under the same conditions, i.e., filling the specimen chamber with artificial saliva and load settings of $49 \mathrm{~N}$. The software parameters were set at $60 \mathrm{~mm} / \mathrm{s}, 3 \mathrm{~mm}$ vertical path, $0.7 \mathrm{~mm}$ horizontal path, and $1.6 \mathrm{~Hz}$ according to the settings used in the previous studies which used implant-retained overdenture models. ${ }^{20,21}$ Each overdenture was subjected to bi-axial cyclic loading for a total of 240,000 cycles in wet conditions at room temperature. 


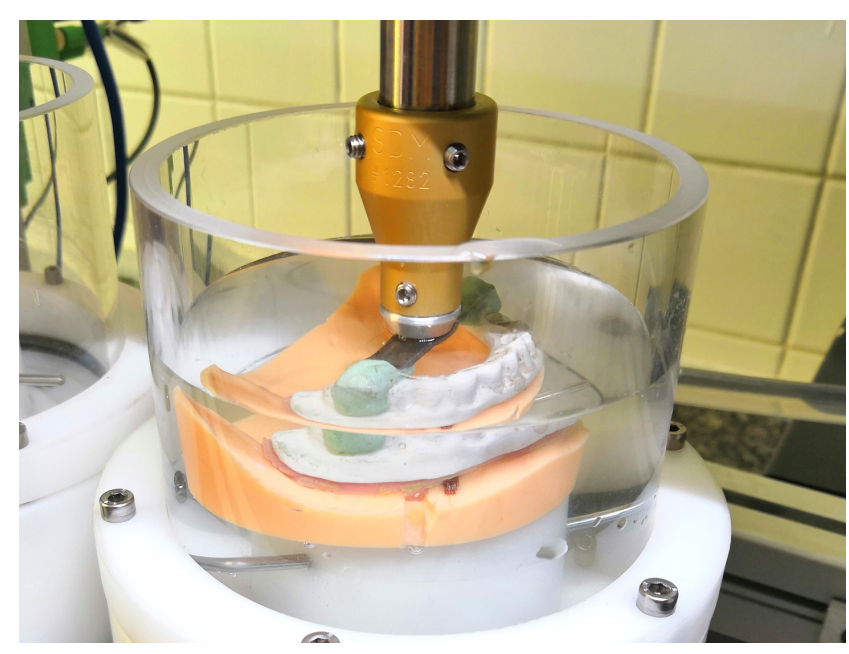

Fig. 4. Point of load application in the center of the metal plate

Each overdenture was inserted and removed 1,440 times, and mounted again in the universal testing machine to measure the final retentive force. Three additional measurements were performed for each overdenture and their mean was considered as the final retention value after the simulation of 1 year of overdenture use.

Data analyses were carried out using Student's $t$ test and paired $t$ test for comparisons between the 2 groups as well as to study changes within each group before and after the simulation of 1-year use. The significance level was set at $p \leq 0.05$.

\section{Results}

The retentive values calculated before chewing simulation were considered as the initial retentive forces, while those recorded after chewing simulation and cyclic dislodgment were considered as the final retentive forces. The mean reduction in the retentive forces in the 2 groups was calculated as percentage.

The mean initial retentive force for the Bio group was $6.19 \mathrm{~N}$ and for the Ti group $-16.64 \mathrm{~N}$. The mean final retentive force for the Bio group was $5.26 \mathrm{~N}$ and $12.92 \mathrm{~N}$ for the Ti group. The mean percentage of the retention force reduction after the simulation of 1 year in function was $15.02 \%$ in the Bio group and $22.44 \%$ in the Ti group. The mean $(M)$ and standard deviation $(S D)$ values of the retentive forces in both groups are listed in Table 1. Figure 5 and Fig. 6 show the minimum, maximum and mean values of the retentive forces as well as the mean percentage reduction in the retention forces for both groups.

The statistical analysis showed that the initial and final retentive forces in the Ti group were significantly higher as compared to the Bio group $(p<0.001$ and $p=0.001$, respectively). There was a statistically significant decrease in the retentive forces after the simulation of 1 year in function in both groups (group Bio: $p=0.041$; group Ti: $p=0.004)$. A higher percentage of reduction in the retention force was observed in the Ti group as compared
Table 1. Retention force values in the 2 groups

\begin{tabular}{|l|c|c|c|}
\multicolumn{1}{|c|}{ Variable } & Abutment & $M \pm S D$ & SEM \\
\hline & $\begin{array}{c}\text { BioHHP } \\
(n=6)\end{array}$ & $\begin{array}{c}6.1933 \\
\pm 2.01288\end{array}$ & 0.82175 \\
\hline $\begin{array}{l}\text { Initial } \\
\text { retentive value [N] }\end{array}$ & $\begin{array}{c}\text { titanium } \\
(n=6)\end{array}$ & $\begin{array}{c}16.6367 \\
\pm 3.38784\end{array}$ & 1.38308 \\
& BioHHP & 5.2633 & \\
& $(n=6)$ & \pm 1.98457 & 0.81020 \\
Final & titanium & 12.9217 & 1.35174 \\
retentive value [N] & $(n=6)$ & \pm 3.31107 & \\
& BioHHP & 15.0245 & 4.14499 \\
Percentage & $(n=6)$ & \pm 10.15311 & \\
of reduction [\%] & titanium & 22.4444 & 3.79872 \\
& $(n=6)$ & \pm 9.30491 & \\
\hline
\end{tabular}

M - mean; SD - standard deviation; SEM - standard error of mean.

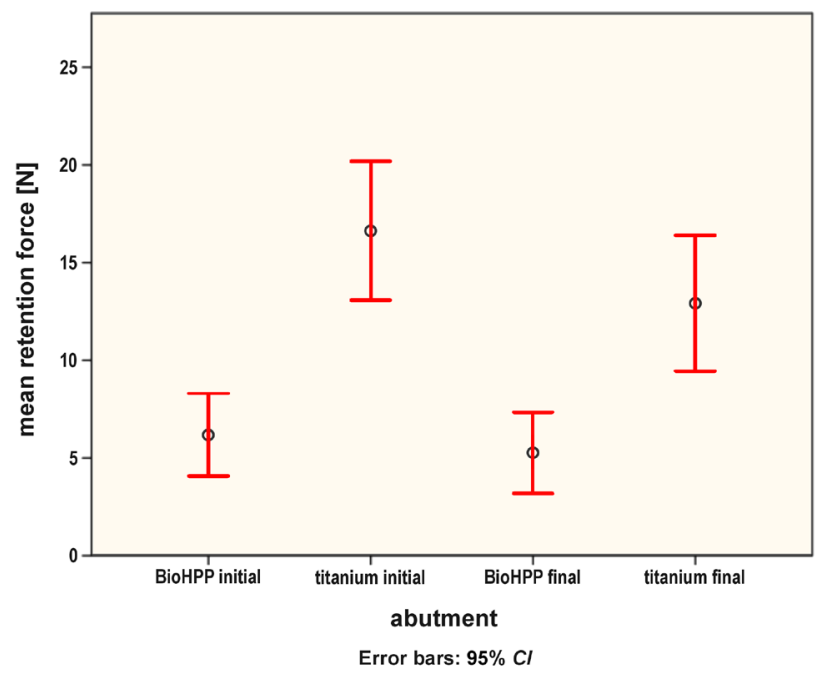

Fig. 5. Error bar showing the minimum, maximum and mean initial and final retention force values in the 2 groups

Cl-confidence interval.

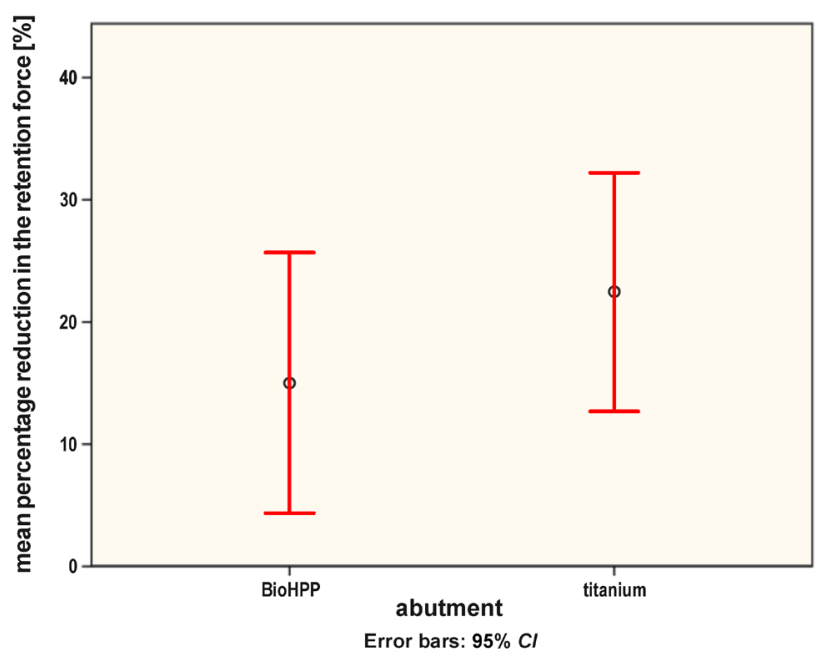

Fig. 6. Error bar showing the minimum, maximum and mean percentage reduction in the retention force values in the 2 groups

to the Bio group, but there was no statistically significant difference between the 2 groups $(p=0.216)$. The results of Student's $t$ test and the paired $t$ test for changes in the retention force values for each group are listed in Table 2. 
Table 2. Results of Student's $t$ test and the paired $t$ test

\begin{tabular}{|c|c|c|c|c|c|}
\hline \multirow{2}{*}{ Retention force } & \multirow{2}{*}{$t$} & \multirow{2}{*}{ df } & \multirow{2}{*}{$p$-value } & \multicolumn{2}{|c|}{$95 \% \mathrm{Cl}$ of the difference } \\
\hline & & & & lower & upper \\
\hline $\begin{array}{l}\text { Initial } \\
\text { (BioHPP * titanium) }\end{array}$ & -6.491 & 10 & 0.000 & -14.02793 & -6.85874 \\
\hline $\begin{array}{l}\text { Final } \\
\text { (BioHPP * titanium) }\end{array}$ & -4.860 & 10 & 0.001 & -11.16977 & -4.14690 \\
\hline $\begin{array}{l}\text { Percentage of reduction in the retention force } \\
\text { (BioHPP * titanium) }\end{array}$ & -1.320 & 10 & 0.216 & -19.94736 & 5.10754 \\
\hline $\begin{array}{l}\text { BioHPP } \\
\text { (initial * final) }\end{array}$ & 2.739 & 5 & 0.041 & 0.05719 & 1.80281 \\
\hline $\begin{array}{l}\text { Titanium } \\
\text { (initial * final) }\end{array}$ & 4.943 & 5 & 0.004 & 1.78296 & 5.64704 \\
\hline
\end{tabular}

$d f$ - degrees of freedom.

\section{Discussion}

The experimental models in this study were manufactured using the 3D printing technology, as it offers the operator freedom in choosing every detail in the model, including the location of implant beds. ${ }^{22}$ The abutments of the $1^{\text {st }}$ group were fabricated from pressed BioHPP on a titanium base. It has been established that BioHPP can be used as an alternative material for the fabrication of abutments and prosthetic restorations, as it has a modulus of elasticity similar to human bone and a hardness value of $30-40 \mathrm{HV},{ }^{23}$ in addition to its good mechanical properties. ${ }^{17}$ Titanium pre-milled abutments were chosen in the $2^{\text {nd }}$ group. Titanium is considered the gold standard abutment material; it is characterized by high mechanical and wear resistance with a hardness value of 350-370 $\mathrm{HV}^{23}$ Besides, pre-milled abutments allow for free customization of the abutment design.

The design of the abutments was prepared with a wall taper angle of 2 degrees and a chamfer finish line for better adaptation and fitting between the copings, and to increase the retention forces. ${ }^{24}$ Glandosane was used as artificial saliva due to its unique effect on the retention force of the telescopic attachment and its role in simulating real oral conditions - specifically its tri-biological effect on the materials and the removal of debris from the wear and tear of the materials. ${ }^{18,19,25}$ To simulate 1 year of function, the number of chewing cycles in this study was 240,000, which was based upon the average number of chewing cycles expected in a year. ${ }^{26}$ Accordingly, the overdentures were inserted and removed 1,440 times, as if they were placed and removed 4 times per day for a year. ${ }^{27}$

Our results rejected the null hypothesis, as they revealed higher initial and final retentive force values in the $\mathrm{Ti}$ group over the Bio group. The difference in the initial retentive forces could be attributed to the pressing process of BioHPP abutments, which was complicated, with many potential sources for errors. Also, the higher final retentive force values in the Ti group could be due to the already higher initial retentive forces as compared to the Bio group.
It has been postulated that any attachment system is subjected to functional loads; it can be attributed to the friction between the telescopic copings, which leads to lowering the retentive force values. Several studies reported a decrease in the retentive force values of different telescopic attachments at the end of the experimental procedures, which supports the results of the present study. ${ }^{19,24,28}$ Also, it has been postulated that the retentive force should be at a level that will not damage the implants or the bone. Furthermore, it has been recommended that the retentive forces in telescopic overdentures should be kept within the range of 5-10 N. ${ }^{25}$ Both groups in our study attained their final retentive force values within the recommended range.

A decline in the retentive force values after the simulation of 1 year of overdenture use was higher in the Ti group as compared to the Bio group. This may have resulted from the wear which occurred in the fitting surfaces of the framework after the simulated functional use in the Ti group due to a difference in the hardness values between the 2 materials. In the Bio group, mechanical adaptation between the primary and secondary copings with the same hardness values resulted in less wear, in addition to strong wedging action between the 2 copings after functional use. ${ }^{25,29}$ However, there was no significant difference in the decrease of the retentive force values after the simulation of 1 year of overdenture use between the 2 groups.

\section{Conclusions}

Within the limitations of the study, it can be concluded that in implant-retained telescopic overdentures supported by 2-degree angle abutments, the retentive force values significantly decreased after the simulation of 1 year of overdenture use. BioHPP and titanium are both considered suitable materials for customized abutments to retain BioHPP telescopic implant overdentures. 


\section{ORCID iDs}

Rania Ramadan (10) https://orcid.org/0000-0003-0850-2542 Yasmine Elsherbeeny (i) https://orcid.org/0000-0001-6888-2028 Yasmine Thabet (10) https://orcid.org/0000-0002-3244-0313 Bassem Kandil (1) https://orcid.org/0000-0002-0643-856X Rami Ghali (ㅇ) https://orcid.org/0000-0003-2356-3220

\section{References}

1. Carlsson GE. Clinical morbidity and sequelae of treatment with complete dentures. J Prosthet Dent. 1998;79(1):17-23. doi:10.1016/s0022-3913(98)70188-x

2. MacEntee MI, Walton JN, Glick N. A clinical trial of patient satisfaction and prosthodontic needs with ball and bar attachments for implant-retained complete overdentures: Three-year results. JProsthet Dent. 2005;93(1):28-37. doi:10.1016/j.prosdent.2004.10.013

3. Heckmann SM, Winter W, Meyer M, Weber HP, Wichmann MG. Overdenture attachment selection and the loading of implant and denture-bearing area. Part 1: In vivo verification of stereolithographic model. Clin Oral Implants Res. 2001;12(6):617-623. doi:10.1034/j.1600-0501.2001.120610.x

4. Heckmann SM, Schrott A, Graef F, Wichmann MG, Weber HP. Mandibular two-implant telescopic overdentures. Clin Oral Implants Res. 2004;15(5):560-569.doi: 10.1111/j.1600-0501.2004.01064.x

5. Wenz HJ, Hertrampf K, Lehmann KM. Clinical longevity of removable partial dentures retained by telescopic crowns: Outcome of the double crown with clearance fit. Int J Prosthodont. 2001;14(3):207-213.

6. Verma R, Joda T, Brägger U, Wittneben JG. A systematic review of the clinical performance of tooth-retained and implantretained double crown prostheses with a follow-up of $\geq 3$ years. J Prosthodont. 2013;22(1):2-12. doi:10.1111/j.1532-849X.2012.00905.x

7. Gomes AL, Montero J. Zirconia implant abutments: A review. Med Oral Patol Oral Cir Bucal. 2011;16(1):e50-e55. doi:10.4317/medoral.16.e50

8. Patil R. Zirconia versus titanium dental implants: A systematic review. J Dent Implants. 2015;5(1):39-42. doi:10.4103/0974-6781.154430

9. Abrahamsson I, Berglundh T, Glantz PO, Lindhe J. The mucosal attachment at different abutments. An experimental study in dogs. $J$ Clin Periodontol. 1998;25(9):721-727. doi:10.1111/j.1600-051x.1998.tb02513.x

10. Alqahtani $F$, Flinton R. Postfatigue fracture resistance of modified prefabricated zirconia implant abutments. J Prosthet Dent. 2014;112(2):299-305. doi:10.1016/j.prosdent.2013.08.023

11. Passos SP, Linke B, Larjava H, French D. Performance of zirconia abutments for implant-supported single-tooth crowns in esthetic areas: A retrospective study up to 12-year follow-up. Clin Oral Implants Res. 2016;27(1):47-54. doi:10.1111/clr.12504

12. Stimmelmayr M, Edelhoff D, Güth JF, Erdelt K, Happe A, Beuer F. Wear at the titanium-titanium and the titanium-zirconia implantabutment interface: A comparative in vitro study. Dent Mater. 2012;28(12):1215-1220. doi:10.1016/j.dental.2012.08.008

13. Gracis S, Thompson VP, Ferencz JL, Silva NRFA, Bonfante EA. A new classification system for all-ceramic and ceramic-like restorative materials. Int J Prosthodont. 2015;28(3):227-235. doi:10.11607/ijp.4244

14. Mehl C, Zhang Q, Lehmann F, Kern M. Retention of zirconia on titanium in two-piece abutments with self-adhesive resin cements. J Prosthet Dent. 2018;120(2):214-219. doi:10.1016/j.prosdent.2017.11.020

15. Wimmer T, Huffmann AMS, Eichberger M, Schmidlin PR, Stawarczyk B. Two-body wear rate of PEEK, CAD/CAM resin composite and PMMA: Effect of specimen geometries, antagonist materials and test set-up configuration. Dent Mater. 2016;32(6):e127-e136. doi:10.1016/j.dental.2016.03.005

16. Hahnel S, Wieser A, Lang R, Rosentritt M. Biofilm formation on the surface of modern implant abutment materials. Clin Oral Implants Res. 2015;26(11):1297-1301. doi:10.1111/clr.12454

17. Bechir ES, Bechir A, Gioga C, Manu R, Burcea A, Dascălu IT. The advantages of BioHPP polymer as superstructure material in oral implantology. Mater Plast. 2016;53(3):394-398.

18. Stock V, Wagner C, Merk S, et al. Retention force of differently fabricated telescopic PEEK crowns with different tapers. Dent Mater J. 2016;35(4):594-600. doi:10.4012/dmj.2015-249

19. Bayer S, Stark H, Mues S, Keilig L, Schrader A, Enkling N. Retention force measurement of telescopic crowns. Clin Oral Investig. 2010;14(5):607-611. doi:10.1007/s00784-009-0315-z
20. Tehini G, Baba NZ, Berberi A, Majzoub Z, Bassal H, Rifai K. Effect of simulated mastication on the retention of locator attachments for implant-supported overdentures: An in vitro pilot study. J Prosthodont. 2020;29(1):74-79. doi:10.1111/jopr.12670

21. Sia PKS, Masri R, Driscoll CF, Romberg E. Effect of locator abutment height on the retentive values of pink locator attachments: An in vitro study. J Prosthet Dent. 2017;117(2):283-288. doi:10.1016/j.prosdent.2016.08.012

22. Karl M, Wichmann MG, Heckmann SM, Krafft T. Strain development in 3-unit implant-supported CAD/CAM restorations. Int J Oral Maxillofac Implants. 2008;23(4):648-652.

23. Sampaio M, Buciumeanu M, Henriques B, Silva FS, Souza JCM, Gomes JR. Comparison between PEEK and Ti6Al4V concerning micro-scale abrasion wear on dental applications. J Mech Behav Biomed Mater. 2016;60:212-219. doi:10.1016/j.jmbbm.2015.12.038

24. Wagner C, Stock V, Merk S, et al. Retention load of telescopic crowns with different taper angles between cobalt-chromium and polyetheretherketone made with three different manufacturing processes examined by pull-off test. J Prosthodont. 2018;27(2):162-168. doi:10.1111/jopr.12482

25. Stock V, Schmidlin PR, Merk S, et al. PEEK primary crowns with cobalt-chromium, zirconia and galvanic secondary crowns with different tapers - a comparison of retention forces. Materials (Basel). 2016;9(3):187. doi:10.3390/ma9030187

26. Heintze SD, Faouzi M, Rousson V, Ozcan M. Correlation of wear in vivo and six laboratory wear methods. Dent Mater. 2012;28(9):961-973. doi:10.1016/j.dental.2012.04.006

27. Guttal SS, Nadiger RK, Abhichandani S. Effect of insertion and removal of tooth supported overdentures on retention strength and fatigue resistance of two commercially available attachment systems. Int J Prosthodont Restor Dent. 2012;2(2):47-51. doi:10.5005/jp-journals-10019-1047

28. Turp I, Bozdağ E, Sünbüloğlu E, Kahruman C, Yusufoğlu I, Bayraktar $G$. Retention and surface changes of zirconia primary crowns with secondary crowns of different materials. Clin Oral Investig. 2014;18(8):2023-2035. doi:10.1007/s00784-013-1183-0

29. Güven $M C ̧$, Tuna M, Bozdağ E, Öztürk GN, Bayraktar G. Comparison of retention forces with various fabrication methods and materials in double crowns. J Adv Prosthodont. 2017;9(4):308-314. doi:10.4047/jap.2017.9.4.308 